\title{
Tidal and sub-tidal sea level variability at the northern shelf of the Brazilian Northeast Region
}

\author{
FELIPE F. FROTA ${ }^{1}$, ELIANE C. TRUCCOLO ${ }^{2}$ and CARLOS A.F. SCHETTINI ${ }^{2}$ \\ ${ }^{1}$ Programa de Pós-Graduação em Oceanografia, Universidade Federal de Pernambuco, Av. \\ Prof. Moraes Rego, 1235, Cidade Universitária, 50670-901 Recife, PE, Brasil \\ ${ }^{2}$ Departamento de Oceanografia, Universidade Federal de Pernambuco, (DOcean/UFPE), Av. \\ Prof. Moraes Rego, 1235, Cidade Universitária, 50670-901 Recife, PE, Brasil
}

Manuscript received on March 2, 2015; accepted for publication on April 29, 2016

\begin{abstract}
A characterization of the sea level variability at tidal and sub-tidal frequencies at the northern shore of the Brazilian Northeast shelf for the period 2009-2011 is presented. The sea level data used was obtained from the Permanent Geodetic Tide Network from the Brazilian Institute of Geography and Statistics for the Fortaleza gauge station. Local wind data was also used to assess its effects on the low-frequency sea level variability. The variability of the sea level was investigated by classical harmonic analysis and by morphology assessment over the tidal signal. The low frequencies were obtained by low-pass filtering. The tidal range oscillated with the highest value of $3.3 \mathrm{~m}$ during the equinox and the lowest value of $0.7 \mathrm{~m}$ during the solstice. Differences between the spring and neap tides were as high as $1 \mathrm{~m}$. A total of 59 tidal constituents were obtained from harmonic analysis, and the regional tide was classified as semi-diurnal pure with a form number of 0.11 . An assessment of the monthly variability of the main tidal constituents $\left(\mathrm{M}_{2}, \mathrm{~S}_{2}, \mathrm{~N}_{2}, \mathrm{O}_{1}\right.$, and $\left.\mathrm{K}_{1}\right)$ indicated that the main semi-diurnal solar $\mathrm{S}_{2}$ presented the highest variability, ranging from 0.21 to $0.41 \mathrm{~m}$; it was the main element altering the form number through the years. The low frequency sea-level variability is negligible, although there is a persistent signal with an energy peak in the 10-15 day period, and it cannot be explained by the effects of local winds.
\end{abstract}

Key words: sea level variability, harmonic constituents, tidal height, Fortaleza, Ceará.

\section{INTRODUCTION}

Sea level is a signal of astronomical, atmospheric, eustatic, and oceanographic forcing acting at wide time and space scales (Gill 1982); tides, seiches, gravity waves, and tsunamis are the most important phenomena affecting coastal areas (Pugh 1987, Church et al. 2008). Knowledge of

Correspondence to: Carlos A.F. Schettini

E-mail: guto.schettini@gmail.com the sea level variability at different time scales is a fundamental need for coastal management, e.g., for harbor activities (Schettini et al. 2011). Tides are particularly important for navigation in shallow areas, where the ship draught is continually increasing and the synchronization of maneuvers and high tide stage can enhance operation safety. Another example is the catastrophic flooding caused by storm surges (Pugh 2004), as occurred 
during the Katrina Hurricane in New Orleans, U.S.A. (Day Jr et al. 2007).

The tidal energy spans on different frequency bands (Munk and Cartwright 1966), although most of the energy is concentrated in the semi-diurnal $(12.42 \mathrm{~h})$ and diurnal $(24.83 \mathrm{~h})$ frequencies, called tidal frequencies (TF) to distinguish them from those that occur at higher frequencies, called supratidal frequencies (SupTF), and those that occur at lower frequencies, called sub-tidal frequencies (SubTF). Most of the coastal sea level variability at SubTF is related to meteorological events, trapped shelf waves, and river discharge (Miranda et al. 2002, Truccolo et al. 2006).

In spite of its importance for coastal management, studies on the sea level variability along the Brazilian Northeast's shores are scarce. In fact, there are only three published studies regarding tides and sea level variability in this region. Lessa et al. (2001) reported the tide characteristics in the Todos os Santos Bay, northern coast of Bahia State; Lessa and Cirano (2006) assessed the hydrodynamics of the Canal Sueste, south of Bahia State, and also provided a characterization of the tides; Schettini et al. (2011) investigated the sea level variability in terms of the joint probability of tides and waves at the Fortaleza coast. This study aims to provide a comprehensive characterization of the sea level variability at the northern shore of the Brazilian Northeast through analysis of the sea level data recorded by the Permanent Tidal Monitoring Network for Geodetics of the Brazilian Institute of Geography and Statistics (IBGE) at Fortaleza. The tide gauge station is located at Porto do Mucuripe, and reflects open sea conditions with very low shallow sea distortions usually observed in tidal records from harbors in restricted seas (e.g., Pugh 1987).

\section{PHYSICAL SETTING}

The northern continental shelf of the Brazilian Northeast (NCS-NE) region encompasses the states of Rio Grande do Norte (RN), Ceará (CE), Piauí (PI), and Maranhão (MA). It can be separated into two main sectors, the Maranhão shelf and the shelf of the other states. The Maranhão shelf is wider with a general E-W orientation and has the "reentrâncias Maranhenses" which is the landward coastline indentation that forms the São Marcos and São José do Ribamar bays. The other sector shows a variable orientation, being E-W in the RN, SE-NE in the east portion of CE, and E-W again in the western portion of CE and PI (Figure 1a). The relief is mild in general, with localized reef formations close to the shore. The shelf width is of the order of $60 \mathrm{~km}$, and the shelf break occurs at nearly $70 \mathrm{~m}$ with an average slope of $2 \mathrm{~m} / \mathrm{km}$ (Freire 1985).

The regional wind regime is strongly modulated by the zonal displacement of the InterTropical Convergence Zone (ITCZ). During the period from August to November, the ITCZ is at a northern position, with the occurrence of strong southeasterly trade winds in the NCS-NE and lower or even a null precipitation rate. During March to May the ITCZ is over the NCS-NE, resulting in weaker northeast trade winds and higher precipitation rates as well (Uvo and Nobre 1989, Castro and Miranda 1998, Campos 2003). The intensification of the southeasterly winds during the dry period intensifies the thermal gradient between land and sea, favoring the occurrence of land/sea breezes (Ferreira 1996). The ITCZ, and as a consequence the wind pattern, is influenced by large-scale oceanographic phenomena such as the Atlantic Dipole and the El Niño-Southern Oscillation (ENSO) cycle (e.g., Cane and Zebiak 1985, Uvo and Berndtsson 1996). The El Niño events - the ENSO warm phase - is associated with dry conditions due to displacement of the 


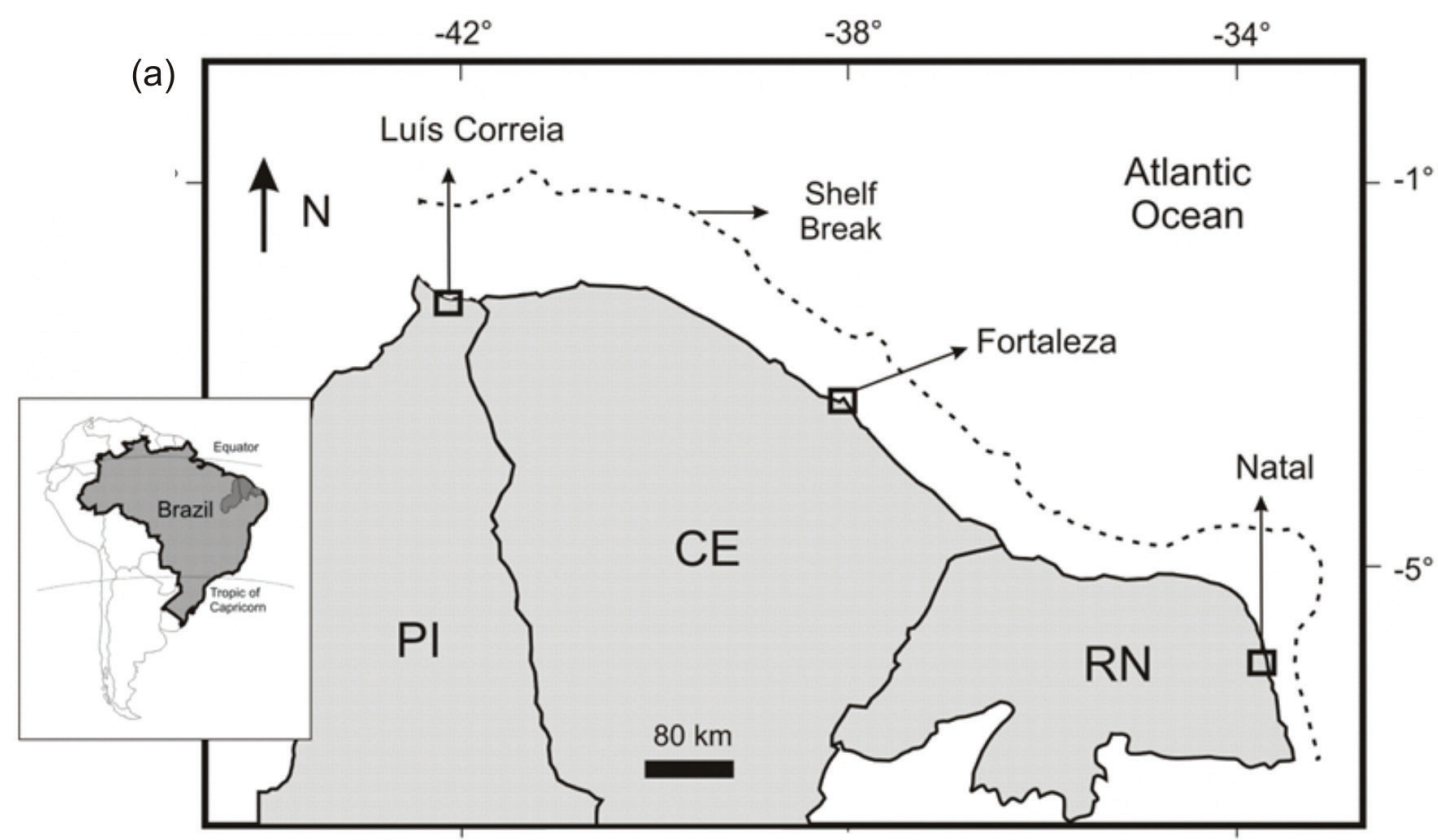

(b)

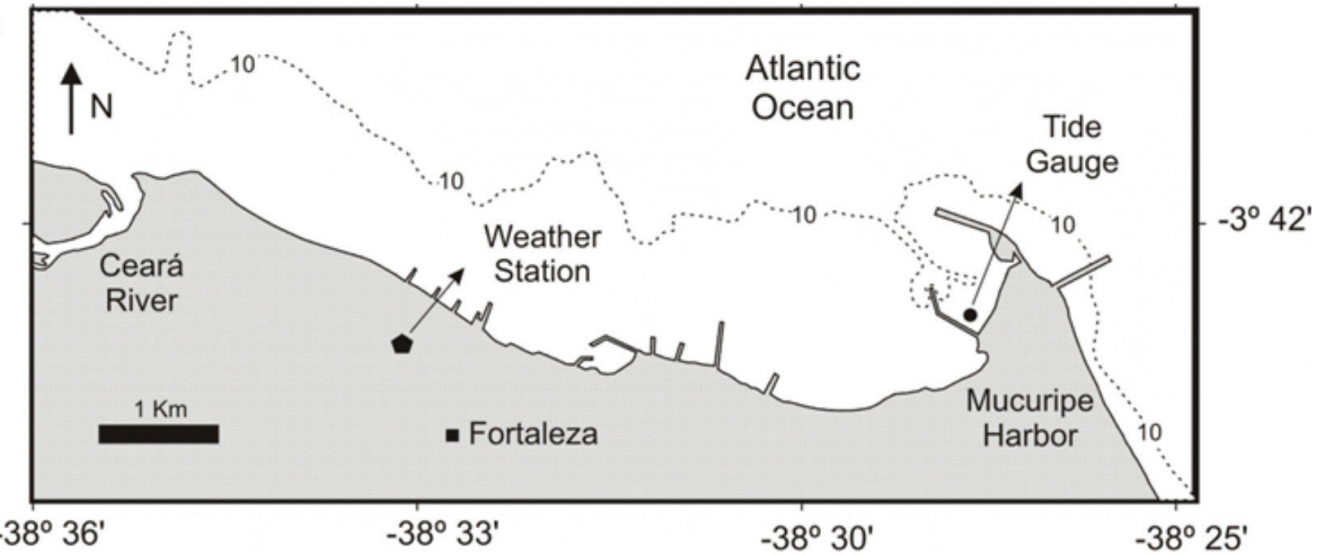

Figure 1 - (a) The northern Brazilian Northeast Continental Shelf and (b) details of the Fortaleza shore showing the tide gauge and meteorological station.

ITCZ further north and a high pressure area in the Northeast region (e.g., Cavalcanti 1996), which also alters the main atmospheric circulations.

The tides in the Tropical Atlantic Ocean are characterized by two main amphidromic systems, one at the north, in the Gulf of Mexico, and the other at the south, in the central portion of the Atlantic basin (Trujillo and Thurman 2011). Figure 2 shows the co-tidal charts of the main semidiurnal constituent, $\mathrm{M}_{2}$, for the tropical Atlantic Ocean provided by Cartwright et al. (1991). Table I shows the main harmonic tidal constituents for Natal $(\mathrm{RN})$, Fortaleza (CE), and Luis Correia (PI). These harmonic constituents were obtained from data sets of 30 days (FEMAR 1999), and show high similarity in terms of relative weight of the semidiurnal ones, and a trend of increase in the range eastward as indicated by the co-tidal chart (Figure 
TABLE I

Main tidal harmonic constituents (amplitudes and phases) for Luis Correia (PI), Fortaleza (CE), and Natal (RN).

\begin{tabular}{|c|c|c|c|c|c|c|}
\hline \multirow[b]{2}{*}{ Tidal Constituent } & \multicolumn{2}{|c|}{ Luis Correia - PI } & \multicolumn{2}{|c|}{ Fortaleza-CE } & \multicolumn{2}{|c|}{ Natal-RN } \\
\hline & $\begin{array}{c}\text { Amplitude } \\
\text { (m) }\end{array}$ & $\begin{array}{c}\text { Phase } \\
\left(^{\circ}\right)\end{array}$ & $\begin{array}{l}\text { Amplitude } \\
\text { (m) }\end{array}$ & $\begin{array}{c}\text { Phase } \\
\left(^{\circ}\right)\end{array}$ & $\begin{array}{l}\text { Amplitude } \\
\text { (m) }\end{array}$ & $\begin{array}{c}\text { Phase } \\
0\end{array}$ \\
\hline $\mathrm{O} 1$ & 0.08 & 192 & 0.07 & 189 & 0.05 & 163 \\
\hline $\mathrm{K} 1$ & 0.09 & 217 & 0.08 & 211 & 0.05 & 235 \\
\hline $\mathrm{P} 1$ & 0.03 & 232 & 0.03 & 211 & 0.02 & 228 \\
\hline M2 & 1.06 & 139 & 0.96 & 132 & 0.81 & 124 \\
\hline MU2 & 0.05 & 106 & 0.04 & 105 & 0.02 & 119 \\
\hline $\mathrm{S} 2$ & 0.34 & 159 & 0.31 & 151 & 0.28 & 142 \\
\hline $\mathrm{N} 2$ & 0.22 & 124 & 0.20 & 115 & 0.17 & 114 \\
\hline $2 \mathrm{~N} 2$ & 0.03 & 116 & 0.03 & 97 & 0.02 & 108 \\
\hline NU2 & 0.04 & 119 & 0.04 & 115 & 0.03 & 116 \\
\hline $\mathrm{K} 2$ & 0.10 & 156 & 0.08 & 151 & 0.08 & 137 \\
\hline
\end{tabular}

(a)

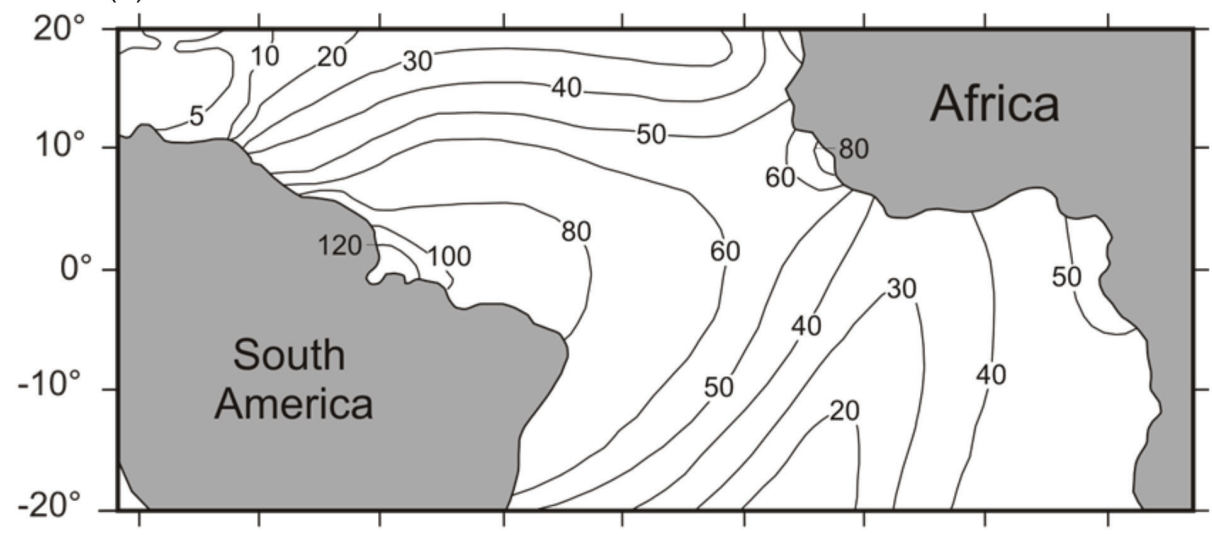

(b)

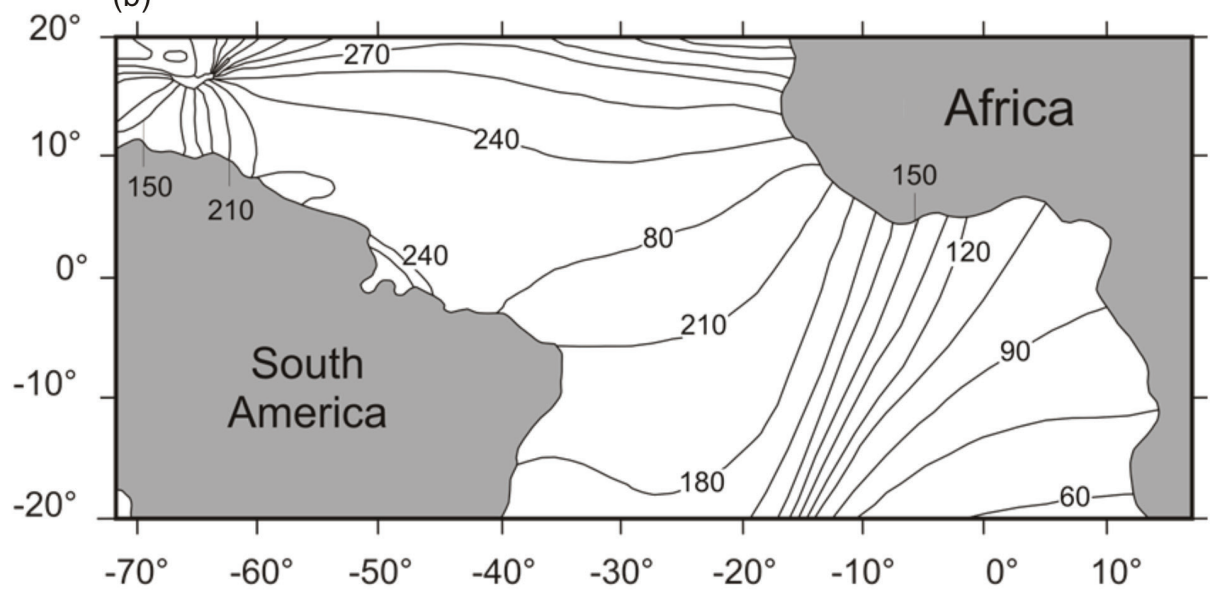

Figure 2 - Co-Tidal chart for the $\mathrm{M}_{2}$ constituent in the tropical Atlantic Ocean. (a) Amplitude in centimeters and (b) phase in degrees to Greenwich. Adapted from Beardsley et al. 1995. 
2). The tide in Fortaleza is pure semi-diurnal, with mean neap and spring tide ranges of 1.5 and $2.8 \mathrm{~m}$, respectively (Schettini et al. 2011).

\section{MATERIALS AND METHODS}

Sea level data was obtained from the tide gauge station at Fortaleza, CE. This tide gauge is part of the Permanent Tidal Monitoring Network for Geodetics of the Brazilian Institute of Geography and Statistics (RMPG-IBGE, acronyms from Portuguese). It is located in the Fortaleza Harbor at $03^{\circ} 42.9^{\prime} \mathrm{S}$ and $38^{\circ} 28.6^{\prime} \mathrm{W}$ (Figure $1 \mathrm{~b}$ ). In contrast to most of the tide gauges along the Brazilian shore, which are located in estuaries, this one is located in a semi-sheltered area that still presents open shore conditions.

The Fortaleza tide gauge station was commissioned in September 2007, with a conventional analogical tidal gauge, providing hourly sea level records. A digital tidal gauge was added in April 2008, providing sea level records at 5 minute intervals. A geodetic GPS was added in August 2008. The station also has a standard RMPG tidal staff, and the tide gauges are assembled in two resting wells. The station is leveled to the national reference level of IBGE. Further details can be accessed at http://www.ibge.gov.br/home/ geociencias/geodesia/default.shtm. In the present study, we analyzed the sea level data recorded from January 2009 to December 2011.

The temporal sea level series were visually inspected to identify spurious signals, missing values, and step changes in the mean sea level. The total amount of errors accounted for less than $0.1 \%$ of the entire record. The missing data periods ranged between a few hours to a day, and were filled by the harmonic signal obtained by the harmonic prediction for the missing period using the Matlab (Mathworks Inc.) T-Tide routines (Pawlowicz et al. 2002, available at http://www2.ocgy.ubc. ca/ rich/\#T_Tide). Sea levels shifts, positive or negative, were corrected by the adjustment of the averaged sea level referenced to the long-term sea level. Figure 3 (a1, b1 and c1) shows the time series of the observed sea level at Porto de Fortaleza for the years 2009, 2010 and 2011 after corrections.

The sea level data, recorded at 5-minute intervals, were reduced to hourly intervals and leveled to the mean level. The sea level data was initially analyzed for its morphometric characteristics by extracting the extreme high (HW) and low (LW) sea level values to obtain a time series of tidal height. The tidal height was obtained by the difference of consecutive LW and $\mathrm{HW}$, and the reference time for a given set of values was the mean time between the respective LW and HW.

The harmonic analysis was performed for each year (2009, 2010, and 2011), and also for each month using a window of 29 days starting always at the first day of each month. For the month of February, data for March $1^{\text {st }}$ was added to complete the window.

The tidal form number (FN), introduced by Courtier (1938, apud Defant 1961), is calculated as the ratio of the sum of the amplitudes, , of the main diurnal harmonic constituents $\left(\mathrm{O}_{1}\right.$ - main diurnal lunar, and $\mathrm{K}_{1}$ - main diurnal solar) to the sum of the main semi-diurnal harmonic constituents $\left(\mathrm{M}_{2}\right.$ - main semi-diurnal lunar, and $\mathrm{S}_{2}$ - main semidiurnal solar),

$$
F N=\frac{\left[a O_{1}+a K_{1}\right]}{\left[a M_{2}+a S_{2}\right]}
$$

FN is used to classify the tide dominance. When $\mathrm{FN}<0.25$, the main tidal regime is semidiurnal pure; when $0.25<\mathrm{FN}<1.5$, the tidal regime is mixed with semi-diurnal dominance; when 1.5 $<\mathrm{FN}<3$, the tidal regime is mixed with diurnal dominance; and when $\mathrm{FN}>3$ the tidal regime is diurnal pure (Defant 1961).

The non-astronomical sea level signal (SubTF) was obtained through the filtration of the 

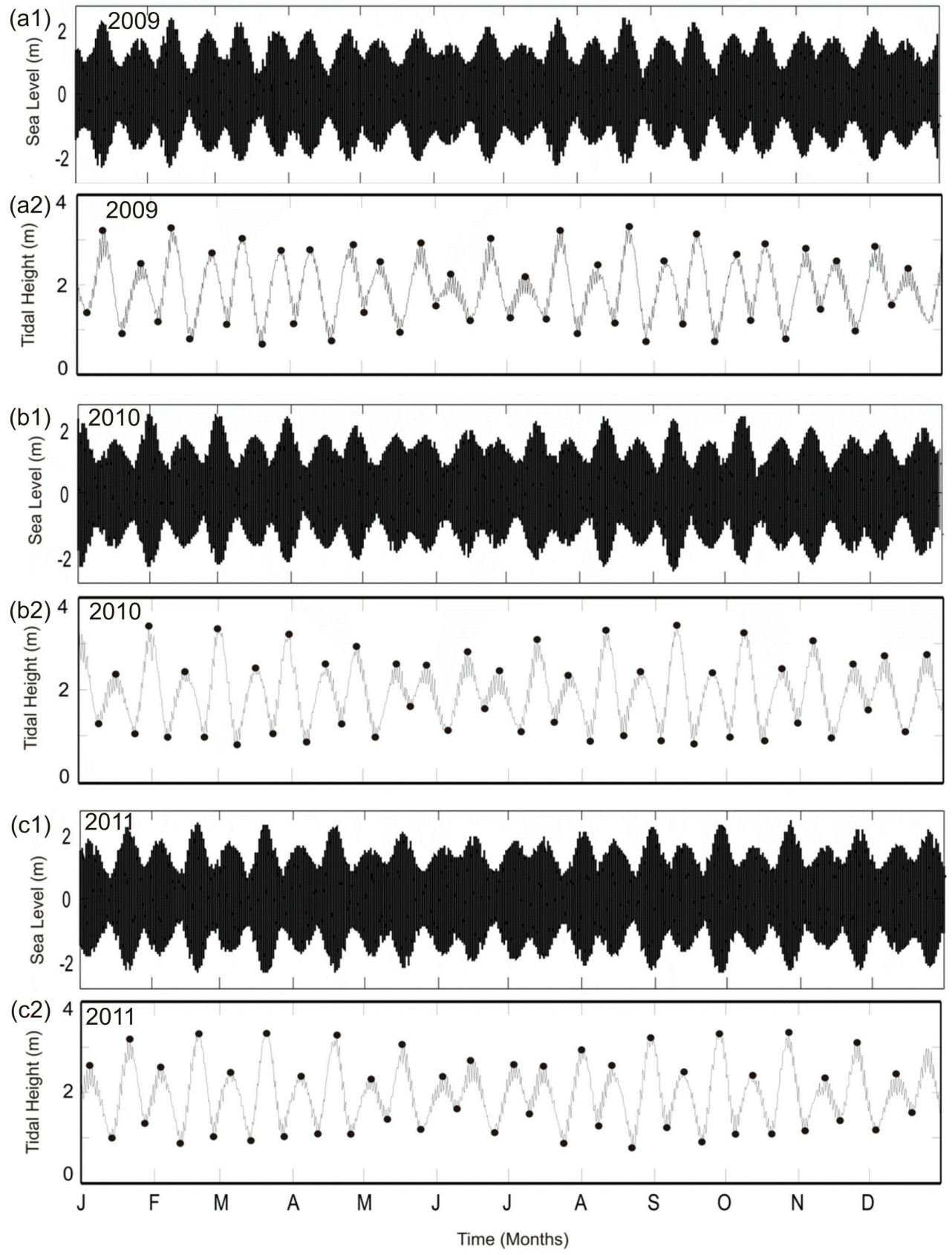

Figure 3 - Observed hourly sea level time series (a1, b1 and c1) and respective tidal height (a2, b2 and c2) at Fortaleza for the years 2009 (a), 2010 (b) and 2011 (c). The black dots at tidal height time series indicate the extreme higher and lower spring and neap tide heights.

original dataset with a temporal window (Walters and Heston 1982), applying a cut frequency smaller than the Nyquist frequency to avoid signal aliasing (Jenkins and Watts 1968, Newland 1975). The cutting frequency used was 48 hours. The signal was also detrended by a linear relationship with time.

Wind speed and direction data were obtained from a meteorological station located in the campus of the Federal University of Ceará (UFC), 
positioned at $03^{\circ} 43^{\prime} \mathrm{S}$ and $38^{\circ} 33^{\prime} \mathrm{W}$ (Fig. 1b). The data is recorded three times per day, at 9, 15, and 21 hours. The location and acquisition rate are not ideal; however, it was the only source of data available. The station is located a few kilometers inshore, and the local topography, the presence of natural and artificial obstacles, variations in the heat fluxes among distinct surfaces, etc., can decrease the wind speed compared to the wind observed offshore (Silva 2003). However, it is still useful since we are looking for some phase agreement between the wind and sea level.

The wind was decomposed in the along and cross-shore components after a rotation by $53^{\circ}$, which is the general orientation of the coastline. The wind components were interpolated by applying the cubic spline method (e.g., Emery and Thomson 1997) to obtain an hourly signal. The spline method segments the time series in smaller parts and applies small order polynomials, and the sum of these polynomials build the interpolated signal over the domain (Mazzini and Schettini 2009). The wind signal was also filtered to SubTF following the same procedure described for the sea level.

The relationship between the wind and sea level was assessed in terms of the yield shear stress over the sea interface. The wind stress, , was obtained by

$$
\tau=\rho_{A} C_{D} W^{2}
$$

where is the density of air $\left(\sim 1.22 \mathrm{kgm}^{-3}\right)$, is the drag coefficient (1.153; Stech and Lorenzetti 1992), and is the wind speed.

The relation between the SubTF wind stress and sea level was investigated by applying the wavelets analysis which allows the identification of not only the frequency energy distribution for a given period, but also the visualization of its variability with time. Like the Fourier analysis, the wavelet gives the wavelet power spectra, cross-wavelet spectra and wavelet coherence and phase spectra, which were calculated following the procedure described in Torrence and Compo (1998), Torrence and Webster (1999) and Grinsted et al. (2004). The wavelets analysis was adapted from the Matlab (Mathworks Inc.) routines available at http://www. pol.ac.uk/home/research/waveletcoherence/. It uses the Morlet wavelet, which uses a continuous function modulated by a Gaussian wave.

\section{RESULTS}

Figure 3 (a2, b2 and c2) shows the time series of the tidal height for the years 2009, 2010, and 2011, with indications (black dots) of the extreme values of the tidal height for the spring and neap tides. The average tidal height was $1.95 \mathrm{~m}$ for the three years. The mean spring tide peak height was 2.79 $\mathrm{m}$, ranging from 2.23 to $3.34 \mathrm{~m}$. The mean neap tide peak height was $1.12 \mathrm{~m}$, ranging from 0.72 to $1.72 \mathrm{~m}$. The largest spring tide heights occurred during the equinox period (March and September), which had the smallest neap tide heights, while the smallest spring tide heights occurred during the solstice period (June and December), which had the largest neap tide heights.

Figure $4 \mathrm{a}$ shows the relationship between the observed and predicted tidal signals for the year 2009 , at hourly intervals. The agreement is very high with the $\mathrm{r}^{2}$ nearly at unity. Therefore, there is some scattering from the $1: 1$ ratio toward the largest heights. For the observed height of $2.5 \mathrm{~m}$, the respective predicted heights range from 2.0 to 3.0 $\mathrm{m}$, although for a limited number of occurrences. Figure $4 \mathrm{~b}$ shows the tidal height occurrence distribution from the observed and predicted signals for the year 2009 and Figure 4c shows the neap and spring tide occurrence distribution from the observed and predicted signals. There is a very good agreement for the tide height and spring tide height occurrences, and therefore, the agreement is not as good for the neap tide heights, where the 

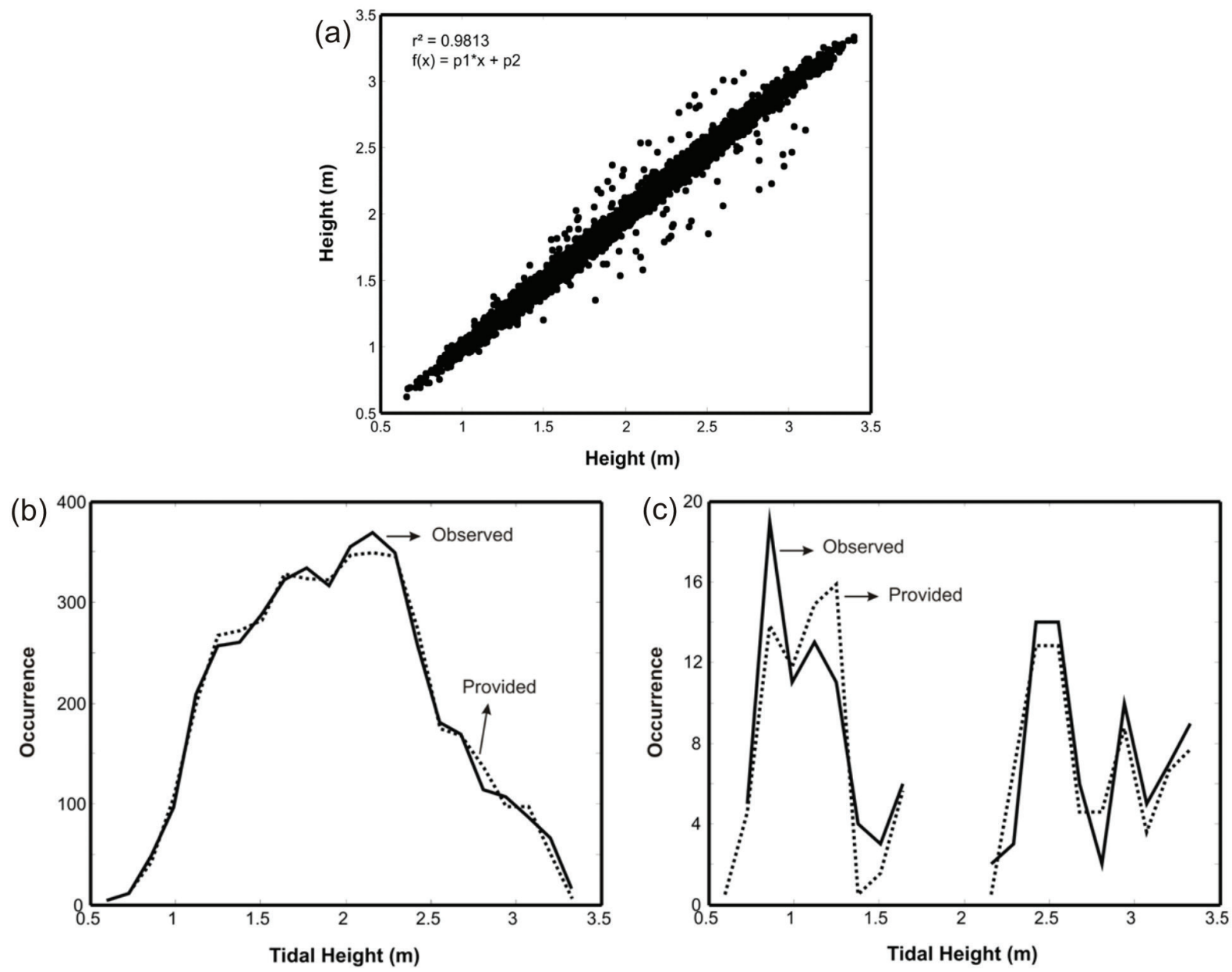

Figure 4 - (a) Relation between the observed and predicted tidal heights. (b) Frequency distribution of observed (full line) and predicted (dashed line) tidal height. (c) Frequency distribution of observed (full line) and predicted (dashed line) of neap and spring tidal height.

mode of the observed heights is smaller than the mode of the predicted heights. The tidal height distribution is asymmetric, with a dominance of heights smaller than $2 \mathrm{~m}$. The main neap tide height mode was about $1.2 \mathrm{~m}$, and the main spring tide height mode was about $2.4 \mathrm{~m}$.

The results of the tidal harmonic analysis performed for the datasets of each year resulted in 59 harmonic constituents. The main diurnal and semi-diurnal harmonic constituents are shown in Table II. There is an excellent agreement among the different years and also with the published harmonic constituents by FEMAR, which is expected because of the constancy of the tidal generating forces and periodicity (Pugh 1987). The averaged maximum potential tidal amplitude was $1.82 \mathrm{~m}$, which can be stated as the sum of the amplitudes of the main constituents shown in Table III. The $\mathrm{M}_{2}$ accounted for $52.5 \%$ of the maximum potential amplitude, while the $\mathrm{S}_{2}$ and the $\mathrm{N}_{2}$, the larger lunar elliptic, have about the same weight, 17.1 and $11.0 \%$, respectively. The $\mathrm{O}_{1}$ and $\mathrm{K}_{1}$ accounted for less than $4 \%$ each. The averaged explained variance of the sea level due to the harmonic constituents was $99.7 \%$. Similar results, in terms of the most important tidal constituents, were reported for the 
TABLE II

Main diurnal and semi-diurnal harmonic constituents for 2009, 2010, and 2011, and the same ones published by FEMAR (1999).

\begin{tabular}{ccccccccc}
\hline & \multicolumn{2}{c}{$\mathbf{2 0 0 9}$} & \multicolumn{2}{c}{$\mathbf{2 0 1 0}$} & \multicolumn{2}{c}{$\mathbf{2 0 1 1}$} & \multicolumn{2}{c}{ FEMAR } \\
\hline $\mathrm{O}_{1}$ & 0.07 & 181 & 0.07 & 182 & 0.07 & 181 & 0.07 & 189 \\
$\mathrm{~K}_{1}$ & 0.07 & 221 & 0.07 & 218 & 0.07 & 220 & 0.08 & 211 \\
$\mathrm{P}_{1}$ & 0.02 & 213 & 0.02 & 215 & 0.02 & 215 & 0.03 & 211 \\
$\mathrm{M}_{2}$ & 0.95 & 131 & 0.96 & 131 & 0.94 & 131 & 0.96 & 132 \\
$\mathrm{MU}_{2}$ & 0.03 & 106 & 0.04 & 105 & 0.04 & 104 & 0.04 & 105 \\
$\mathrm{~S}_{2}$ & 0.31 & 151 & 0.31 & 152 & 0.31 & 152 & 0.31 & 151 \\
$\mathrm{~N}_{2}$ & 0.20 & 117 & 0.20 & 118 & 0.20 & 117 & 0.20 & 115 \\
$2 \mathrm{~N}_{2}$ & 0.03 & 105 & 0.03 & 105 & 0.03 & 107 & 0.03 & 97 \\
$\mathrm{NU}_{2}$ & 0.03 & 117 & 0.03 & 117 & 0.04 & 121 & 0.04 & 115 \\
$\mathrm{~K}_{2}$ & 0.08 & 147 & 0.08 & 147 & 0.08 & 147 & 0.08 & 151 \\
\hline
\end{tabular}

TABLE III

Descriptive tidal parameters derived from harmonic tidal constituents (Values-H)

compared with the values derived from morphology (Values-M). FN: form number; MH: mean tidal height; MSH: mean spring tide height; MNH: mean neap tide height.

\begin{tabular}{ccccc}
\hline Parameter & Formula & Values-H (m) & Values-M (m) & $\boldsymbol{\delta}(\mathbf{m})$ \\
\hline FN & $(\mathrm{K} 1+\mathrm{O} 1) /(\mathrm{M} 2+\mathrm{S} 2)$ & 0.11 & - & $-0.13 / 6 \%$ \\
$\mathrm{MH}$ & $2.2(\mathrm{M} 2)$ & 2.08 & 1.95 & $0.26 / 10 \%$ \\
$\mathrm{MSH}$ & $2.0(\mathrm{M} 2+\mathrm{S} 2)$ & 2.53 & 2.79 & $-0.14 / 11 \%$ \\
$\mathrm{MNH}$ & $2.0(\mathrm{M} 2-\mathrm{S} 2)$ & 1.26 & 1.12 & \\
\hline
\end{tabular}

Amazon shelf by Beardsley et al. (1995). Table III shows these parameters derived from the tidal constituents.

It is noticeable in Figure 3 that there is a strong anomalistic modulation caused by the $\mathrm{N}_{2}$, which implies synodical inequalities. This means that there is a height difference between consecutive spring or neap tides. Figure 5 shows the temporal variability of the height difference between consecutive spring and neap tides, depicted as dots in Figure 3 (a2, b2 and c2). There is a polarity inversion between the maximum spring tide height differences and the neap tide ones, or, when the maximum difference occurs in the spring tides, the smallest is observed in the neap tides, and viceversa. The inversions occur with a period larger than 6 months. During the period analyzed, the maximum height differences of the spring tide occurred in January and July of 2009, February and September of 2010, and April and November of 2011. This effect is due to the nodal regression of the Moon, which has a period of 18.61 years (Pugh 1987). Taking the mean spring tide height from the morphometry $(2.8 \mathrm{~m})$ as reference, the spring tide height variability can be as high as $1 \mathrm{~m}$, or $36 \%$ of the mean value.

The time series of along and cross-shore wind velocity components and the sea level at SubTF for 2009 are shown in Figure 6 (a, b and c). The maximum along, , and cross, , -shore wind velocity were 4.3 and $9.6 \mathrm{~ms}^{-1}$, respectively, and the mean values were nearly null and $2.2 \mathrm{~ms}^{-1}$, respectively. 


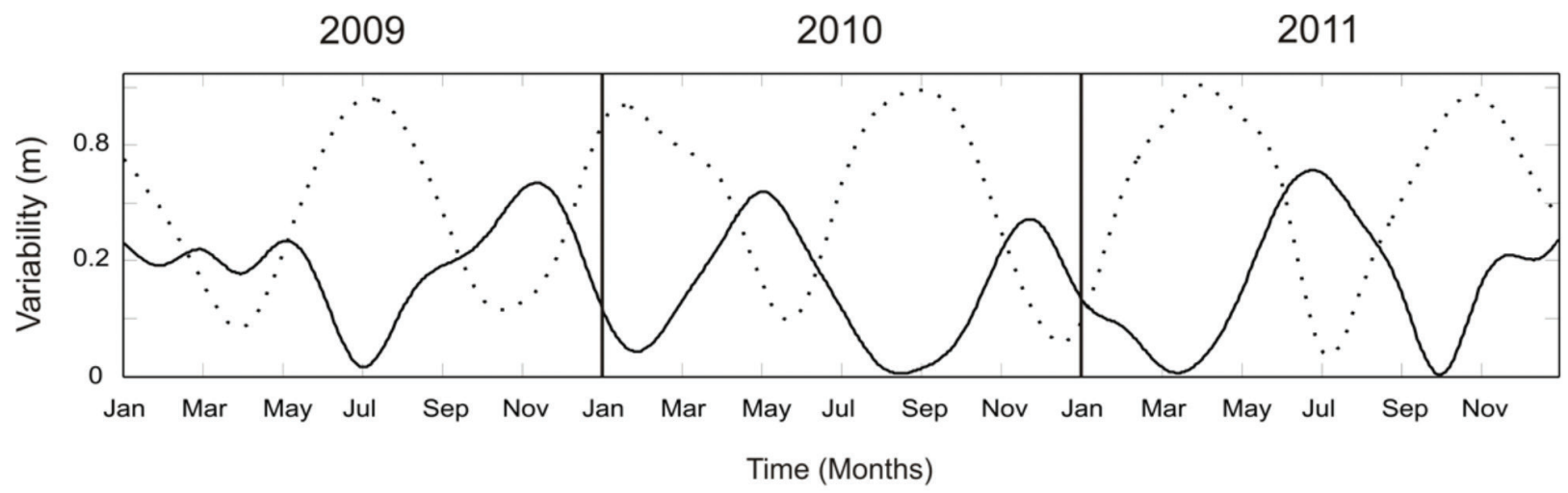

Figure 5 - Temporal variability between consecutive neap (full line) and spring (dashed line) tides for the years 2009,2010 and 2011.

There is an annual modulation of the wind velocity. The lowest velocity of and were recorded between April and June. The highest wind velocities were recorded between September and November. The sea level variability at SubTF was very low, with a maximum of $0.12 \mathrm{~m}$. Therefore, there are still oscillations apparently not related to the wind.

The wavelet power spectra of the sea level and the wind shear stress, and the wavelet coherence and phase spectrum between them are shown in Figure 6 (c, $d$ and e). The $\mathrm{x}$-axis represents time and the $y$-axis the period in 'days'. The side areas with transparency indicate the cone of influence (the inner part) where the analysis is valid. The color pattern indicates the energy, increasing to the red. A black line separates the regions where the levels of significance are higher than $5 \%$. The level of significance of the coherence spectrum was estimated using the Monte Carlo method. The arrows in the coherence spectrum indicate the phase between the series. Arrows pointing to the right denote that the series are in phase, while arrows pointing to the left denote that the series are $180^{\circ}$ out of phase. The coherence spectrum is the square of the smoothed cross spectrum, normalized with the smoothed wavelet spectrum. This procedure provides the interval of coherence between 0 and 1 , where a value of one indicates maximum coherence (Torrence and Webster 1999). The application of the coherence and phase spectrum allows the visualization of the regions of higher covariance, in contrast to the cross-wavelet, which reveals common regions of higher energy between series (Truccolo 2009).

The sea level power spectrum shows a region of higher energy within the periods between 10 and 15 days for most of the time, and other scattered to lower time-periods during all the year. The wind stress power spectrum shows higher energy for the periods below 10 days, except for the period of April/May when the energy was the lowest, which is related to the lowest wind velocity (Figure $6 c, d$ and e). There was an increase of energy at higher periods for the period of 10 to 20 days for the period between August and October. The only region of the coherence spectrum coinciding with higher energy in the sea level power spectrum was for March-April with periods of 10-15 days. Therefore, there is no significant energy in the wind power spectrum.

\section{DISCUSSION}

The world's shores can be classified according to the tidal range, , as microtidal, mesotidal and macrotidal, when $<2.0 \mathrm{~m}, 2.0<<4.0 \mathrm{~m}$, and $>4.0 \mathrm{~m}$, respectively (Davies 1964), or, in a similar fashion, as microtidal, lower mesotidal, upper mesotidal, lower macrotidal and upper macrotidal, when < 

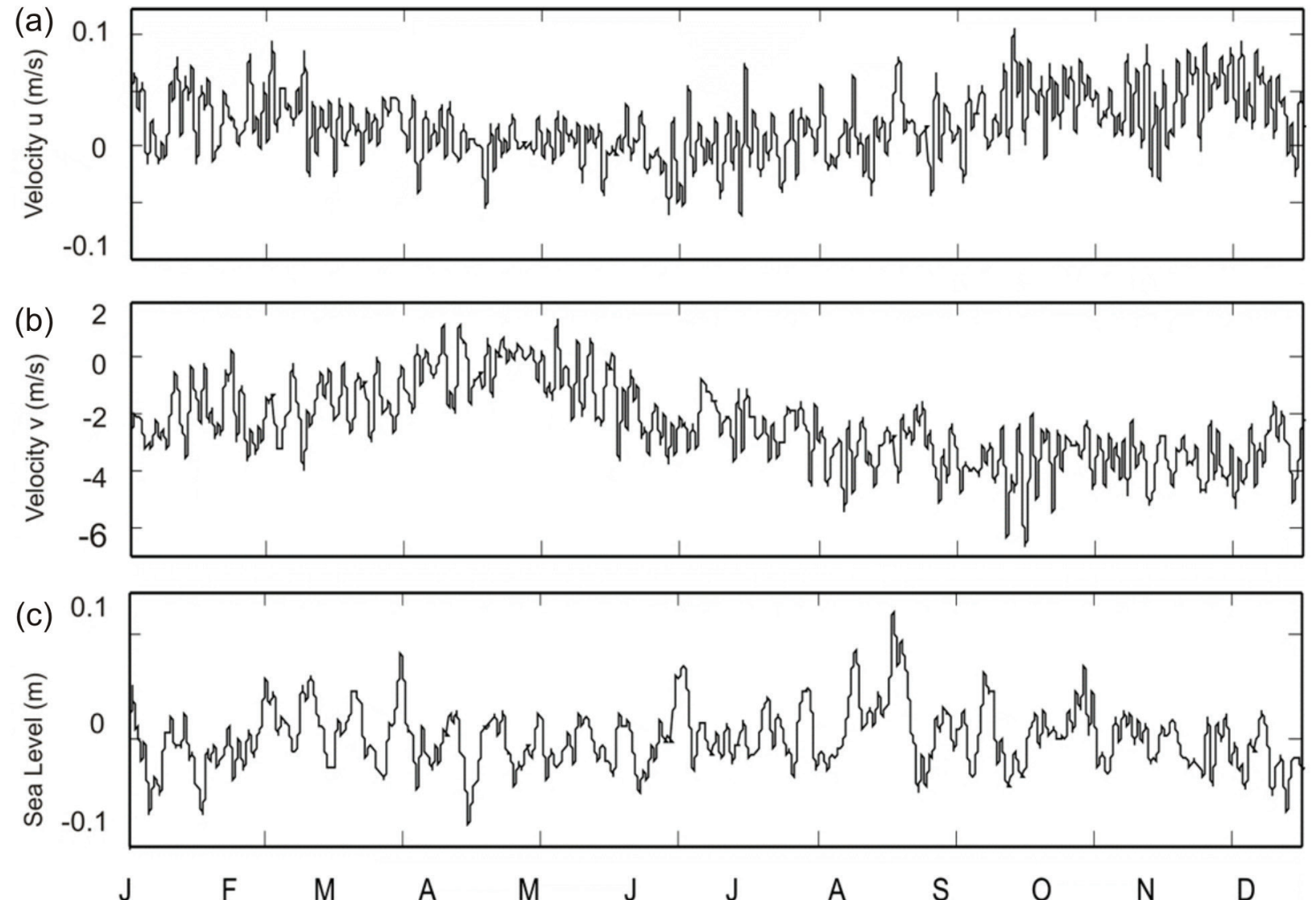

Time (Months, 2009)

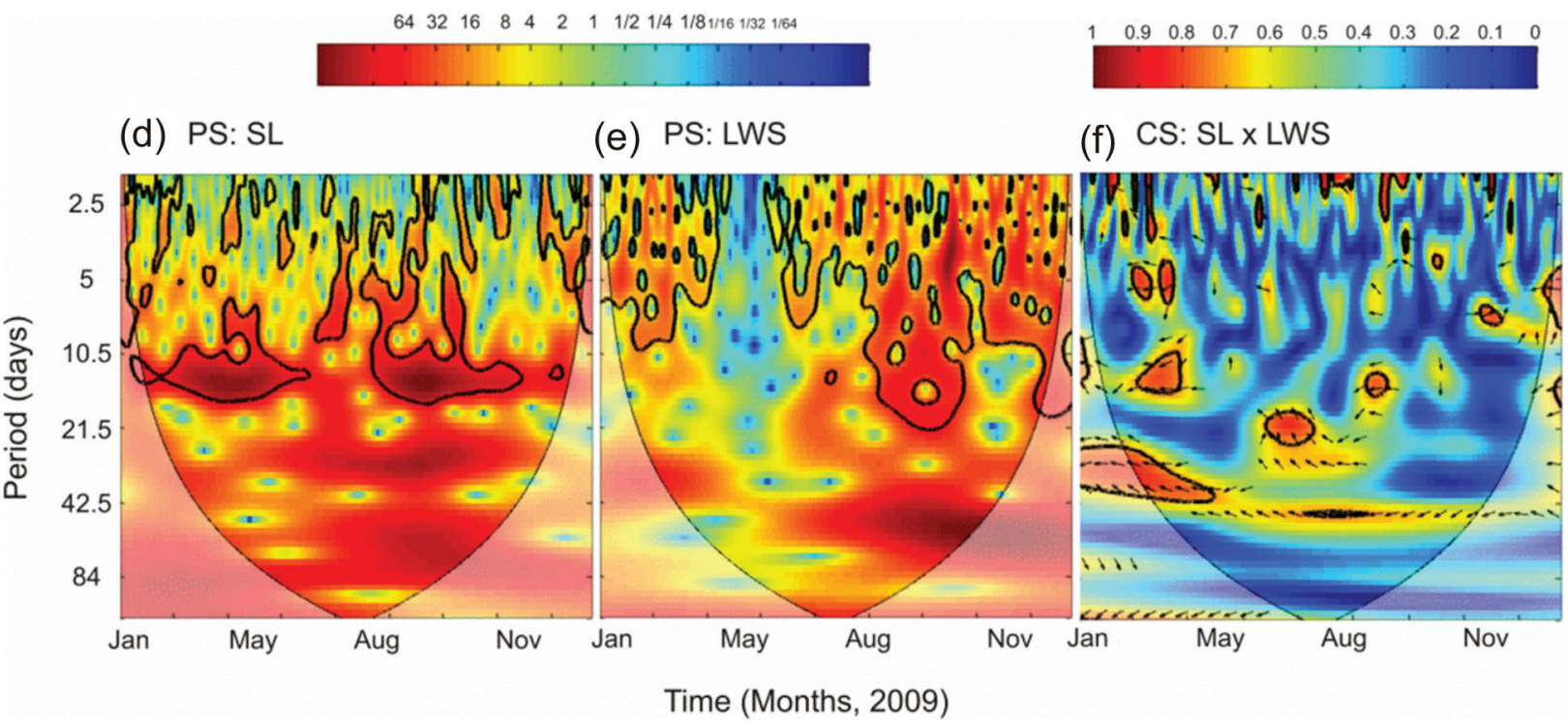

Figure 6 - Time series of sub-tidal signals of (a) alongshore and (b) cross-shore wind velocity components and (c) sea level. Wavelet power spectra (PS) of (d) sea level (SL) and (e) alongshore wind stress (LWS), and (f) wavelet coherence and phase spectrum (CS) between wind stress and sea level. 
$1.0 \mathrm{~m}, 1.0<<2.0 \mathrm{~m}, 2.0<<3.5 \mathrm{~m}, 3.5<<5.5$ $\mathrm{m}$, and $>5.5 \mathrm{~m}$, respectively (Hayes 1979). These classifications are useful since they qualitatively weight the role of tides, and consequently the tidal energy controlling the coastal processes, providing a basis for coastal management. This is particularly relevant especially when one considers the scenarios of sea-level rise (e.g., Pethick 2001).

The basic approach to classify a given stretch of shore is to obtain a time series of sea level for a period of at least 30 days, from which the main harmonic tidal constituents can be determined, and from them, the basic descriptive parameters of the tide (Table III). These parameters provide a robust characterization of the tide in average terms, in error bounds of about $10 \%$ compared with observed values in the present case. Therefore, there is an intrinsic tidal variability that must be accounted to better describe the phenomenon. In the present study, we analyzed a time series of three years of sea level recorded in nearly open sea, which represent the shelf tides very well. Almost all the sea level variance was explained by tidal harmonic constituents, which were compared with tidal morphologic parameters. The tidal harmonic analysis is robust in obtaining coefficients from a time series, although it will never reproduce the original time series perfectly.

With the application of the traditional tidal descriptive parameters (Table III), we obtained a mean tidal height of $2.05 \mathrm{~m}$, which is about $7 \%$ larger than the value obtained from the tidal morphology. The calculated mean spring and neap tide height were about $10 \%$ smaller and larger, respectively, from those obtained from morphology. In spite of the relatively small difference between the calculated and observed values, this difference is, fortuitously in the present case, enough to change the regional shore classification. Even this is not necessarily an important issue regarding physical coastal processes the misclassification may suggest to someone that the tides are more important than it really is.

The variability around the mean spring and neap tide values is usually not considered. In the present case, the neap tides can be $52 \%$ higher or $36 \%$ lower than the mean, and the spring tides can be about $20 \%$ higher or lower than the mean value. As shown in Figure 7, the tidal height difference between consecutive spring tides can be as high as $1 \mathrm{~m}$, and 0.7 between consecutive neap tides. The main cause of such variability is related to the importance of the $\mathrm{N}_{2}$, which is nearly equivalent to the $\mathrm{S}_{2}$. The $\mathrm{N}_{2}$ represents the effects of the elliptic orbit of the Moon, with a period of 27.55 days. Thus, in the period of a lunar month, the distance between the Earth and Moon varies, and when the Moon is closest to the Earth (apogee), the tidal generating forces will be stronger, while in the opposite case (perigee), they will be weaker (Pugh 1987).

The diurnal inequalities can be important as well. Diurnal inequalities are due to the interactions between diurnal and semi-diurnal constituents, which are weighted by the tidal form number. The tidal constituents are not constant through the year, and consequently the form number changes too. Figure 7a shows the annual variability of the main diurnal $\left(\mathrm{O}_{1}, \mathrm{~K}_{1}\right)$ and semi-diurnal $\left(\mathrm{M}_{2}, \mathrm{~S}_{2}\right.$ and $\mathrm{N}_{2}$ ) harmonic tidal constituents. The $\mathrm{O}_{1}, \mathrm{~K}_{1}, \mathrm{M}_{2}$, and $\mathrm{N}_{2}$ show a relatively small variability around their mean values, while the $\mathrm{S}_{2}$ varies much more, between 0.2 and 0.4 . The variability ratio, given by the ratio of the standard deviation and the mean, was 0.11 , and due to the annual variation of the $\mathrm{S}_{2}$ amplitude, it ranges from 0.08 in March to 0.13 in June (Figure 7b).

A practical aspect concerning the understanding of the tidal variability is related to the sampling strategies assessing the hydrodynamics and scalar transport processes in estuaries (e.g., Kjerfve 1990), especially when the continent-ocean biogeochemical fluxes are being estimated (e.g., Pereira-Filho et al. 2001, Schettini and Miranda 

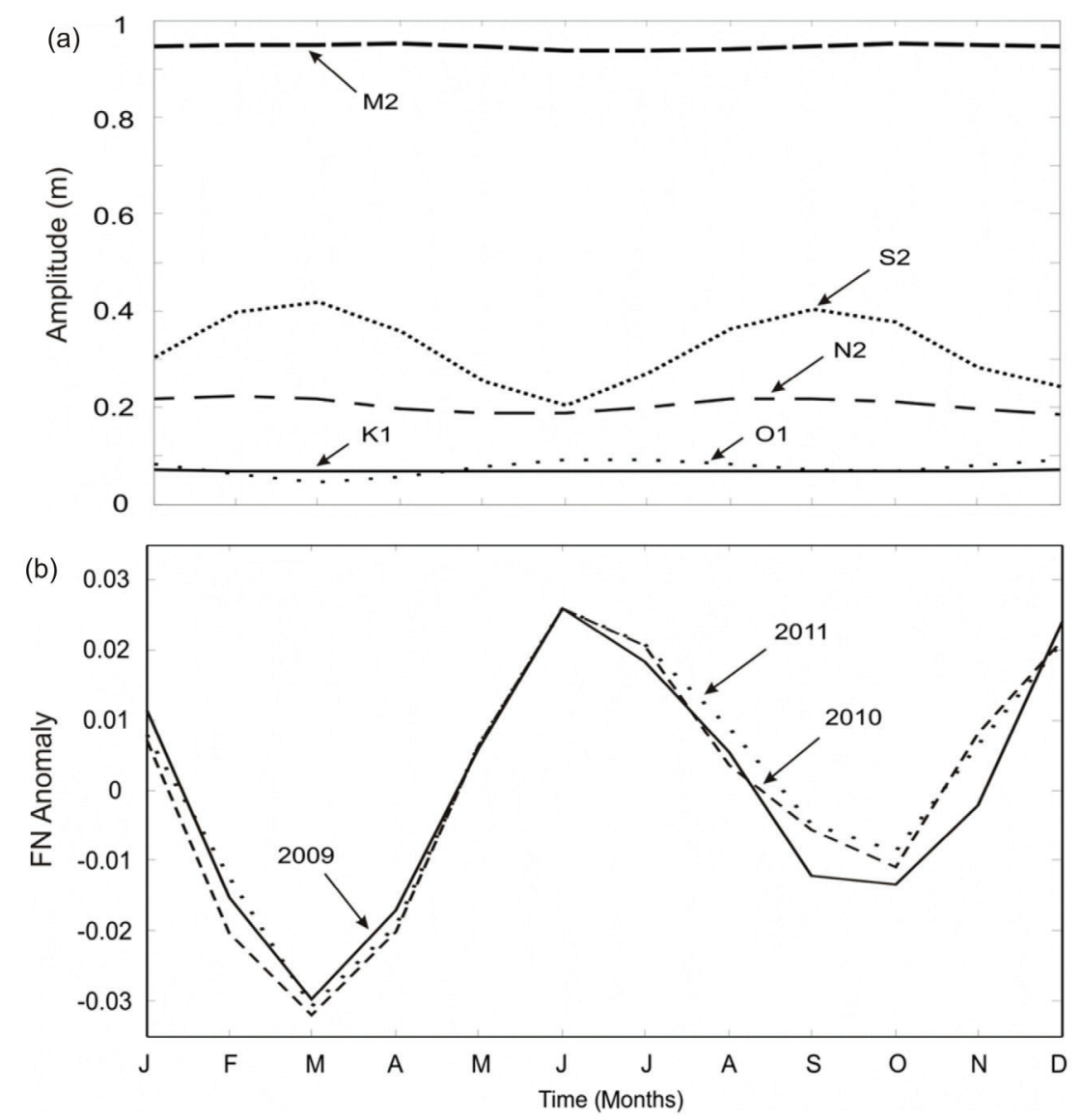

Figure 7 - (a) Monthly variation of the amplitude of the main diurnal $\left(\mathrm{O}_{1}, \mathrm{~K}_{1}\right)$ and semidiurnal $\left(\mathrm{M}_{2}, \mathrm{~S}_{2}\right.$ and $\left.\mathrm{N}_{2}\right)$ tidal constituents averaged for the years 2009, 2010 and 2011. (b) Monthly variation of the tidal form number anomaly (full line: 2009; dashed line: 2010; dotted line: 2011).

2010). The sampling strategy is usually based on sampling sea level, current velocity and direction, salinity, and several other scalars in a cross-section during at least one complete tidal cycle to obtain the instantaneous volume transport and the scalar mass transport. This approach furnishes the intratidal variability (e.g., Schettini et al. 2006), and the time-averaged values give the residual transport by elimination of the oscillatory character of the tidal variability. The latter is a very important result as it can highlight whether a system is a source or a trap for a specific scalar (Shubel and Carter 1984, Schettini et al. 2013), which can be extrapolated to obtain long-term trends. Therefore, the robustness of this result is strongly dependent on the sampling strategy.

Along shores subjected to pure semi-diurnal tides $(\mathrm{FN}<0.4)$, it has been demonstrated that sampling during a single tidal cycle ( $\sim 13$ hours) is sufficient to obtain robust residual fluxes, since the semi-diurnal inequalities are small (Kjerfve 1990). This strategy has many logistic advantages, since an experiment can be performed during daylight (it is safer), can be run by a single team, and it is cheaper than a 25-hour or longer experiments. Therefore, especially in arid and semi-arid shores where the estuaries are under a low-inflow regime (e.g., Largier 2010) and the residual fluxes are due 
mainly to the tidal regime and are expected to be small, even small tidal inequalities can introduce a bias in the residual flux estimation. Studies aiming to obtain fluxes based on 13-hour surveys would achieve better results if sampling is conducted in May and October when the FN number and tidal inequalities are smaller (Figure 4).

Another important aspect associated with tidal experiments to estimate fluxes is that they must be performed at hydrological and tidal modal conditions. This means that experiments should be performed during the lower and higher periods of river inflow to the estuary, which depends on the annual hydrological regime (e.g., Pereira et al. 2010), and at spring and neap tides, which present current velocity extremes (Byun et al. 2013). Regarding the tides, usually the most extreme conditions are sought to visualize the wider spectrum of tidal effects, or, sampling is performed during the larger spring and smallest neap tide, consecutively (the order doesn't matter). These extremes occur during the equinoxes, at March and September, and do not coincide with the minimum FN periods. Additionally, the synodical inequalities should also be considered, since the range difference between consecutive spring/neap tides can be important, and will change on a yearly basis in a cycle of about 20 years.

Non-astronomical effects on the sea level are irrelevant at the study area. In spite of this, it is notable that there still is a SubTF that produces oscillations of $0.1 \mathrm{~m}$ in amplitude, and it is even more interesting that these oscillations have spectral energy concentrated in the 10-15 day period. The explanation of this variability is beyond the scope of the present paper, although some hypothesis can be put forth. The coherence spectrum between the local wind stress and sea level indicates that these oscillations are not due to the local response through Ekman mechanism, however, this result doesn't discard the idea that remote winds could have produced them (e.g.,
Truccolo et al. 2006). According to Shetye and Vijith (2013), there are two known mechanisms for generating sea level oscillations at the continental shelf: geostrophic adjustment of a remotely forced current and oscillations forced by local winds that could be ageostrophic. Since the continental shelf is relatively narrow along this stretch, it is possible that some sea level oscillations could be related to the continental shelf waves (due to remotely wind effect) and the variability of the North Brazil current-NBC (e.g., Stramma and Schott 1999). The NBC flowing westward at the continental margin produces rings (Philander and Pacanowski 1986), and the passage of these rings could affect somewhat the shelf sea level. At the shore of the Amazon, the synodical constituent MSf is relatively important (Gallo and Vinzon 2005). The SubTF oscillations recorded in Fortaleza ( 1,000 km eastward) may be associated with both effects, although with the energy spanned from the harmonic frequency due to non-linear interactions with the NBC and shelf morphology.

\section{CONCLUSIONS}

The tidal regime along the northern shelf of the Brazilian Northeast region can be classified as an intermediate state between micro and mesotidal (e.g., Davies 1964) or upper mesotidal regimes (e.g., Hayes 1979). The tidal height ranges from 0.7 (the minimum neap tide height) to $3.3 \mathrm{~m}$ (the maximum spring tide height). In the present study, the use of a relatively simple morphology assessment over the observed and/or predicted (based on a 365-day analysis) data provided a useful insight into the harmonic tidal variability.

The morphology assessment from both, observations and harmonic prediction, furnish similar results in terms of the frequency distribution of height, although some scattering at higher tidal heights is present. The histograms of the neap and spring tide also do not correlate very well. 
The descriptive tidal parameters from the harmonic constituents work well for the mean tidal range; however, there are overestimations/ underestimations of about $10 \%$ for the mean spring/ neap tidal height.

The $\mathrm{S}_{2}$ annual variation produces a reflex in the form number, with the maximum semi-diurnal inequalities occurring during May and October. The $\mathrm{N}_{2}$ synodical inequalities can be as large as 1 $\mathrm{m}$ between consecutive spring tides.

The non-harmonic sea level oscillations are negligible. Nevertheless, there is a persistent oscillation of about $0.1 \mathrm{~m}$ with energy concentrated in the 10-15 day period.

\section{ACKNOWLEDGMENTS}

We are thankful to the Instituto Brasileiro de Geografia e Estatística (IBGE) for making the sea level data freely available; to the Universidade Federal do Ceará (UFC) for the meteorological data. FFF has a Conselho Nacional de Desenvolvimento Científico e Tecnológico (CNPq) scholarship; ECT has a $\mathrm{CNPq}$ and Fundação de Amparo à Ciência e Tecnologia do Estado de Pernambuco (FACEPE) DCR scholarship; CAFS has a CNPq scholarship PQ 308665/2013-9.

\section{REFERENCES}

BEARDSLEY RC, CANDELA J, LIMEBURNER R, GEYER WR, LENTZ SJ, CASTRO BM, CACCHIONE D AND CARNEIRO N. 1995. The M2 tide on the Amazon shelf. J Geophys Res-Oceans 100: 2283-2319.

BYUN D-S, HART DE AND JEONG W-J. 2013. Tidal current energy resources off the South and West coasts of Korea: Preliminary observation-derived estimates. Energies 6: 566-578.

CAMPOS AA. 2003. A zona costeira do Ceará: Diagnóstico para a gestão integrada. Fortaleza - CE: Ed. Aquasis, 248 p.

CANE MA AND ZEBIAK SE. 1985. A theory for El Nino and the Southern Oscillation. Science 2(28): 1085-1087.

CARTWRIGHT DE AND RAY RD. 1991. Energetics of global ocean tides from Geosat altimetry. J Geophys ResOceans 96: 16897-16912

CASTRO BM AND MIRANDA LB. 1998. Physical oceanography of the western Atlantic Continental Shelf located between $4^{\circ} \mathrm{N}$ and $34^{\circ} \mathrm{S}$ coastal segment $(4, \mathrm{~W})$. In: Robinson AR and Brink KH (Eds), The Sea, New York: Ed. J Wiley \& Sons, New York, USA, p. 209-251.

CAVALCANTI IFA. 1996. Episódios El Niño/Oscilação Sul durante a década de 1986 a 1996 e suas influências sobre o Brasil. In: CLIMANÁLISE ESPECIAL: EDIÇÃO COMEMORATIVA DE 10 ANOS, São José dos Campos: INPE/CPTEC, SP, p. 52-64.

CHURCH JA, WHITE NJ, AARUP T, WILSON WS, WOODWORTH PL, DOMINGUES CM, HUNTER JR AND LAMBECK K. 2008. Understanding global sea levels: past, present and future. Sustain Sci 3(1): 9-22.

DAVIES JL. 1964. A morphogenic approach to world shorelines. Zeitschrift für Geomorphology Mortensen Sonderheft 8: 127-142.

DAY JR JW ET AL. 2007. Restoration of Mississippi delta: lessons from hurricanes Katrina and Rita. Science 315(5819): 1679-1684.

DEFANT A. 1961. Physical Oceanography, v. 2, New York: Pergamon Press, 598 p.

EMERY W AND THOMSON R. 1997. Data Analysis in Physical Oceanography. New York: Pergamon Press, 634 p.

FEMAR - FUNDAÇÃO DE ESTUDOS DO MAR. 1999. Catálogo de estações maregráficas brasileiras. Rio de Janeiro: FEMAR, 95 p.

FERREIRA NS. 1996. Zona de convergência intertropical. In: CLIMANÁLISE ESPECIAL: EDIÇÃO COMEMORATIVA DE 10 ANOS. FORTALEZA: FUNCEME, p. 136-139.

FREIRE GSS. 1985. Geologia marinha da plataforma continental do estado do Ceará. Dissertação de Mestrado. Universidade Federal de Pernambuco. Recife, 162 p. (Unpublished).

GALLO MN AND VINZON SB. 2005. Generation of overtides and compound tides in Amazon estuary. Ocean Dynam 55(5-6): 441-448.

GILL AE. 1982. Atmosphere-ocean dynamics. International Geophysics Series. v. 30, London: Academic Press, 662 p.

GRINSTED A, MOORE JC AND JEVREJEVA S. 2004. Application of the cross wavelet transform and wavelet coherence to geophysical time series. Nonlinear Proc Geoph 11: 561-566.

HAYES MO. 1979. Barrier island morphology as a function of tidal and wave regime. In: Leatherman SP (Ed), Barrier islands. New York: Academic Press, p. 1-27.

JENKINS GM AND WATTS DG. 1968. Spectral analysis and its applications. San Francisco, CA: Holden-Day, 525 p.

KJERFVE B. 1990. Manual for Investigation of Hydrological Processes in Mangrove Ecosystems. New Delhi: Unesco, 79 p.

LARGIER JL. 2010. Low-inflow estuaries: hypersaline, inverse, and thermal scenarios. In: Valle-Levinson A (Ed), Contemporary issues in estuarine physics. Cambridge: Cambridge Press, p. 247-272. 
LESSA GC AND CIRANO M. 2006. On the circulation of a coastal channel within the Abrolhos Coral-Reef system Southern Bahia. J Coastal Res SI 39(SI): 450-453.

LESSA GC, DOMINGUEZ JML, BITTENCOURT ACSP AND BRICHTA A. 2001. The tides and tidal circulation of Todos os Santos Bay, northeast Brazil: a general characterization. An Acad Bras Cienc 73: 245-261.

MARMER HA. 1954. Tides and sea level in the Gulf of Mexico. Fish B-NOAA 55 (89): 101-118.

MARTIN L, DOMINGUEZ JML AND BITTENCOURT ACSP. 1998. Climatic control of coastal erosion during a sea-level fall episode. An Acad Bras Cienc 70: 249-266.

MAZZINI PLF AND SCHETTINI CAF. 2009. Avaliação de metodologias de interpolação espacial aplicadas a dados hidrográficos costeiros quase-sinóticos. Braz J Aquatic Sci Tech 13: 53-64.

MIRANDA LB, CASTRO BM AND KJERVE B. 2002. Princípios de oceanografia física de estuários. São Paulo: EDUSP, $424 \mathrm{p}$.

MUNK W AND CARTWRIGHT DE. 1966. Tidal spectroscopy and prediction. Phil Trans R Soc London A 259: 533-581.

NEWLAND DE. 1975. Random vibration and spectral analysis. New York: Longman Group Limited, 285 p.

PAWLOWICZ R, BEARDSLEY B AND LENTZ S. 2002. Classical tidal harmonic analysis including error estimates in MATLAB using T_TIDE. Comput Geosci 28: 929-937.

PEREIRA-FILHO J, SCHETTINI CAF, RÖRIG L AND SIEGLE E. 2001. Intratidal variation and net transport of dissolved inorganic nutrients, POC and chlorophyll a in the Camboriú River estuary, Brazil. Estuar Coast Shelf Sci 53: 249-257.

PEREIRA MD, SIEGLE E, MIRANDA LB AND SCHETTINI CAF. 2010. Hidrodinâmica e transporte de material particulado em suspensão sazonal em um estuário dominado por maré: Estuário de Caravelas, BA. Rev Bras Geof 28: 427-444.

PETHICK J. 2001. Coastal management and sea-level rise. Catena 42(2-4): 307-322.

PHILANDER SG AND PACANOWSKI RC. 1986. A model of the seasonal cycle in the tropical Atlantic Ocean. J Geophys Res-Oceans 14: 192-206.

PUGH DT. 1987. Tides, surges and mean sea level. Swindon, UK: J Wiley \& Sons, 472 p.

PUGH DT. 2004. Changing sea levels. Effects of tides, weather and climate. Cambridge University Press, UK: Cambridge, $280 \mathrm{p}$.

SCHETTINI CAF, MAIA LP AND TRUCCOLO EC. 2011. Análise da variabilidade do nível da água na costa de Fortaleza, Ceará. Arq Cienc Mar 44(1): 27-32.

SCHETTINI CAF AND MIRANDA LB. 2010. Circulation and suspended matter transport in a tidally dominated estuary: Caravelas estuary, Bahia, Brazil. Braz J Oceanogr 58(1): 1-11.

SCHETTINI CAF, PEREIRA MD, SIEGLE E, MIRANDA LB AND SILVA MP. 2013. Residual fluxes of suspended sediment in a tidally dominated tropical estuary. Cont Shelf Res 70: 27-35.

SCHETTINI CAF, RICKLEFS K, TRUCCOLO EC AND GOLBIG V. 2006. Synoptic hydrography of a highly stratified estuary. Ocean Dynam 56: 308-319.

SCHUBEL JR AND CARTER HH. 1984. The estuary as a filter for fine-grained suspended sediment. In: Kennedy VS (Ed), The estuary as a filter. New York: Academic Press, p. 81-105.

SHETYE SR AND VIJITH V. 2013. Sub-tidal water-level oscillations in the Mandovi estuary, west coast of India. Estuar Coast Shelf Sci 134: 1-10.

SILVA G. 2003. Características do vento da região Nordeste: análise, modelagem e aplicações para projetos de centrais eólicas. Dissertação de Mestrado. Universidade Federal de Pernambuco, Recife, 141 p. (Unpublished).

STECH JL AND LORENZETTI JA. 1992. The response of south Brazil bight to the passage of wintertime cold fronts. J Geophys Res-Oceans 97: 9507-9520.

STRAMMA LAND SCHOTT F. 1999. The mean flow field of the tropical Atlantic Ocean. Deep-Sea Res PT II 46(1-2): 279-303.

TORRENCE C AND COMPO GP. 1998. A pratical guide to wavelet analysis. B Am Meteorol Soc 79(1): 61-78.

TORRENCE C AND WEBSTER PJ. 1999. Interdecadal changes in the ENSO-Moonson system. J Climate 12: 2679-2680.

TRUCCOLO EC. 2009. Hidrodinâmica em frequência mareal e sub-mareal do estuário do Rio Itajaí-Açu. Tese de Doutorado. Universidade Federal do Rio Grande do Sul, 180 p.

TRUCCOLO EC, FRANCO D AND SCHETTINI CAF. 2006. The low frequency sea level oscillations in the northern coast of Santa Catarina, Brazil. J Coast Res SI 39: $547-$ 552.

TRUJILLO AP AND THURMAN HV. 2011. Essentials of oceanography. v. 10, New Jersey: Prentice Hall Recommended Reading Walker, 576 p.

UVO CB AND BERNDTSSON R. 1996. Regionalization and spatial properties of Ceará state rainfall in northeast Brazil. J Geophys Res-Climate 101: 4221-4233.

UVO CRB AND NOBRE CA. 1989. A zona de convergência intertropical (ZCIT) e a precipitação no norte do nordeste do Brasil. Parte I: A Posição da ZCIT no Atlântico Equatorial. Climanalise 4(7): 34-40.

WALTERS RA AND HESTON C. 1982. Removing the tidalperiod variations from time-series data using low-pass digital filters. J Phys Oceanogr 12: 112-115. 